\title{
Detection of asthma and chronic obstructive pulmonary disease in primary care
}

\author{
C.P. van Schayck, N.H. Chavannes
}

Detection of asthma and chronic obstructive pulmonary disease in primary care. C.P. van Schayck, N.H. Chavannes. (C) ERS Journals Ltd 2003.

ABSTRACT: Chronic obstructive pulmonary disease (COPD) and asthma are major health problems, the number of patients with these diseases is still rising and only $25-50 \%$ of these patients are known to their doctors.

Lung function gradually decreases in COPD and asthmatic patients during their lives. Due to adaptation of the patients or due to the doctor being unaware of the symptoms, COPD is often diagnosed late in its course and when finally diagnosed, lung function is often relatively poor. Underdiagnosis and consequently undertreatment might play an important role in the increase in morbidity and mortality as a result of COPD and asthma. Early detection and treatment might improve the long-term prognosis of these patients and this secondary prevention may also prevent irreversible loss of function.

The identification of patients is useless if no effective preventive measures are available. In asthma, inhaled corticosteroids have been shown to have distinct effects on the progression of the disease. However, in COPD inhaled corticosteroids have only been shown to have some effects and the long-term effects on lung function have been disappointing. At present, the most effective treatment available for COPD is the cessation of smoking. It appears that a smoker at risk of developing COPD is more motivated to stop smoking than someone who is not at risk and this may help a physician in encouraging an attempt to quit.

General practitioners appear to be already using this knowledge, as they seem more likely to advise smokers to quit smoking if they perceive their problems to be smoking related.

Eur Respir J 2003; 21: Suppl. 39, 16s-22s.
Dept of General Practice, Maastricht University, Maastricht, the Netherlands.

Correspondence: C.P. van Schayck Dept of General Practice

Research Institute ExTra

Maastricht University

P.O. Box 616

6200 MD Maastricht

The Netherlands.

Fax: 31433884225

E-mail: onno.vanschayck@hag.

unimaas.nl

\section{Keywords: Asthma}

chronic obstructive pulmonary disease diagnosis

early detection

stop smoking

Received: May 162002

Accepted after revision: June 112002
Chronic obstructive pulmonary disease (COPD) and asthma are major health problems and the worldwide number of patients with these diseases continues to rise [1-5]. According to the Global Burden of Disease Study, COPD will be the fifth leading cause of disability and the third leading cause of death in the world in the first half of the 21 st century. For developing countries, COPD is expected to be the fourth leading cause of disability for males and the third for females in 2020 [6]. Prevalence ranges from $10 \%$, for objective signs of COPD or asthma in the general population [1], to $26 \%$ for chronic airflow obstruction in patients aged $\geqslant 45$ yrs [3], depending on the criteria used. Only $25-50 \%$ of these patients are known to their doctor [1, 4]. The decrease in lung function in patients with COPD (and to some extent in patients with asthma) is gradual during their lives. Due to patients adapting to this gradual decrease [7-9] or due to the doctor not being aware of the symptoms and risk factors, COPD is often diagnosed late in its course [4, 7]. In the developing world, lack of resources, diagnostic facilities and physicians working on a community level, often constitute an even greater obstacle in establishing an early diagnosis. As a result, lung function is often relatively poor when first diagnosed and the forced expiratory volume in one second (FEV1) is sometimes $<50 \%$ of the predicted value $[10,11]$.

Is underdiagnosis a real problem in daily care?

The increase in asthma and COPD incidence seems to apply to both the number of diagnosed and undiagnosed (as yet) patients [1, 12] (fig. 1). Underdiagnosis and consequently undertreatment may play an important role in the increase in morbidity and mortality as a result of asthma or COPD [11-14]. Early detection and treatment might improve the long-term prognosis of these patients [2] and this secondary prevention may also prevent irreversible loss of function [15]. It is not clear what causes underdiagnosis, in other words whether it the physician or the patient who is to blame [16]. Is underdiagnosis of asthma caused by the physician who does not adequately interpret the symptoms presented to him or her, or is it caused by the patient who does not actually present his or her symptoms to the physician? If the latter aspect plays a role, it is not clear why a patient does not present his or her symptoms [17-19]. 

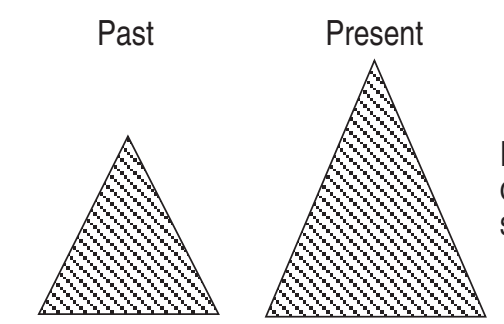

Increase in prevalence observed in registration systems in primary care
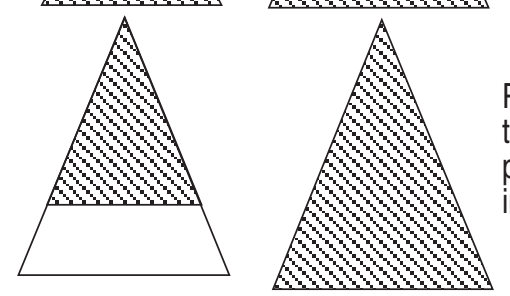

Possible reason for this increased prevalence: improved diagnostics
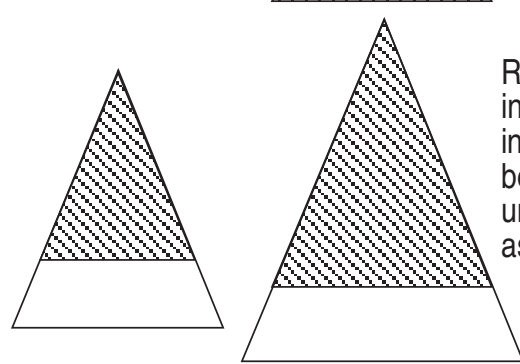

Real reason for this increased prevalence: increased prevalence of both diagnosed and undiagnosed asthma/COPD

Fig. 1.- Prevalence of asthma and chronic obstructive pulmonary disease (COPD) in the general population in 1977 (past) and 1992 (present). $\mathbb{\mathbb { N }}$ : known (registered) morbidity; $\square$ : unknown (registered) morbidity. Data taken from [1].

The Asthma Insights and Reality in Europe study has shown that currently there are major deficiencies in respiratory practice [20]. For example, delays in diagnosis are common [21] and lead to inappropriate treatments being given. In other cases, severity is underestimated with the result that preventive therapy is under-used $[22,23]$. One study showed that $74 \%$ of patients admitted to hospital with severe asthma could have had the admission prevented by different prior care [24]. Already, in the early 1980s, it was established that nearly $90 \%$ of deaths due to asthma involve avoidable factors [25].

\section{What could be the reason for underdiagnosis?}

It seems that the majority of patients with a decreased FEV1 do not complain of any bronchial symptoms [1]. In particular, the slowly progressive nature of COPD appears to lead to diminished awareness of signs of disease. For instance, a smoker's cough each morning or a decreased exercise tolerance in daily activities are both perceived as normal phenomena, accepted during the accumulating years of gradual deterioration. As a result, patients remain unknown to their general practitioner (GP). In addition, the subjects who do present with respiratory problems and have a reduced lung function are not always recognised. In this group the interpretation of the presented complaint has presumably been the wrong one. In looking for possible causes of underdiagnosis of asthma/COPD, the current authors have a)
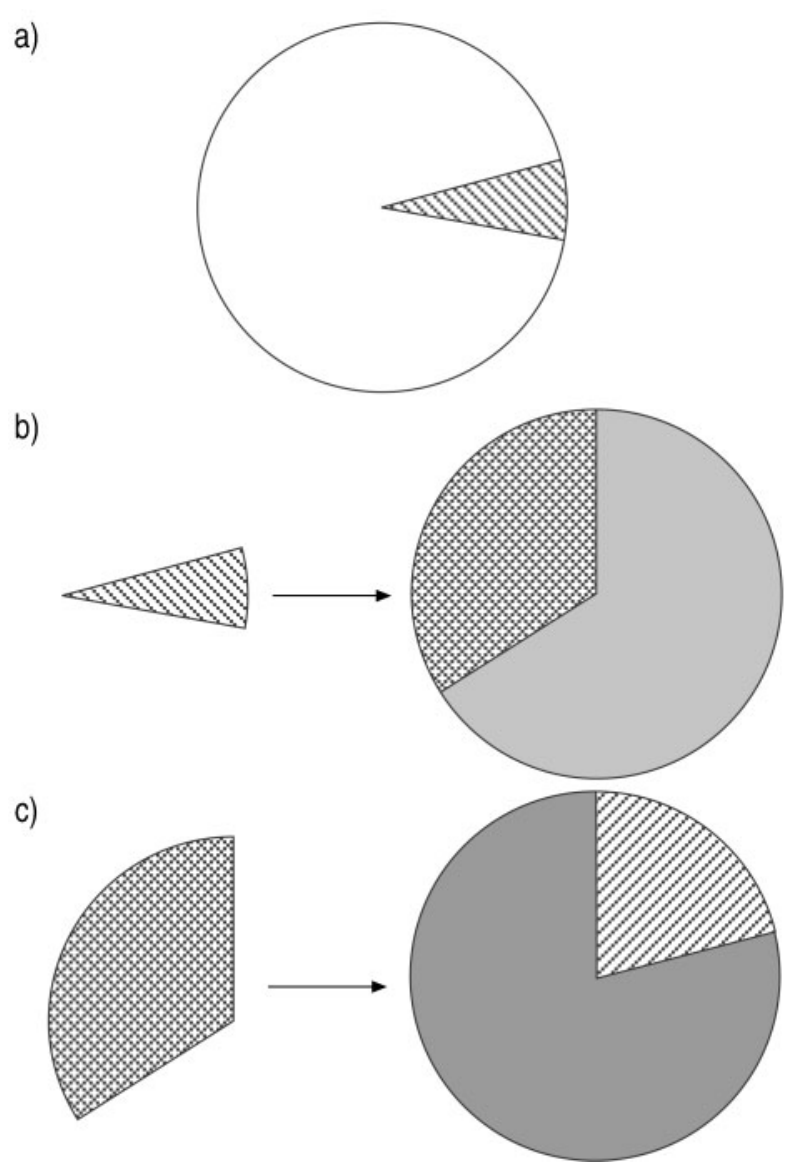

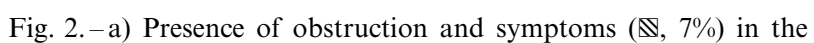
general population $(n=1,150)$. b) From a), the $7 \%$ of subjects with obstruction and symptoms $(\mathrm{n}=86)$ who presented their symptoms . $34 \%$ ) or who did not present their symptoms to the general practitioner (GP) $(\square, 66 \%)$. From b), the 34\% of subjects who presented symptoms that were diagnosed by the GP $(\square, 79 \%)$ and not diagnosed $(\mathbb{Z}, 21 \%)$. Data taken from [26].

observed previously that the problem is mainly due to patient factors and only partly to factors related to the GP [26] (fig. 2). Consequently, these observations signify that only a minority of the total group of subjects with symptoms can potentially be diagnosed by the GP.

Perception seems to determine, at least in part, the presentation of symptoms to the GP [26]. Of a group of subjects with bronchial obstruction who did visit the GP for airway symptoms, $6 \%$ had a poor perception of dyspnoea, while in subjects who did not visit the GP in spite of a bronchial obstruction, this percentage was more than four times as high, i.e. $26 \%$ (fig. 3). It could be argued that poor perception of dyspnoea is a probable cause of underpresentation by patients, so neither the physician nor the patient is to blame for the underdiagnosis of asthma in the general population.

While methods of classifying COPD largely depend upon spirometric measurements, disability is only weakly related to measurements of lung function. Therefore, the need for a simple and standardised method of categorising disability in COPD has emerged [27]. In research, the influence of dyspnoea 


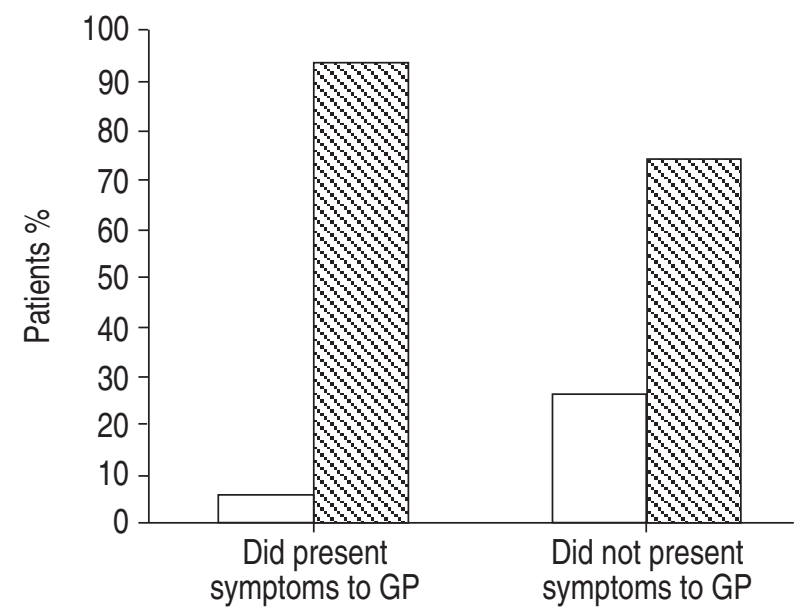

Fig. 3.-Per cent of patients with airflow obstruction who did or did not present their symptoms to the general practitioner (GP) in relation to poor $(\square)$ and good $(\mathbb{\nabla})$ perception of dyspnoea. Data taken from [26].

on health-related quality of life using disease-specific questionnaires has been identified, but these tools are not fit for clinical use. However, factor analysis has demonstrated that clinical dyspnoea ratings, such as the Medical Research Council dyspnoea scale or the Baseline Dyspnoea Index, may well be a substitute for these in cross-sectional assessment [28]. Thus, these simple tools to adequately detect dyspnoea, which are not time consuming, are available and ready for clinical use.

It has been pointed out before that underdiagnosis of asthma is a large problem not only in adults but also in children $[29,30]$. This justifies the further study of more active screening or case finding of asthma in risk groups in general practice [29].

\section{Should asthma/chronic obstructive pulmonary disease be diagnosed earlier?}

There is no sense in screening or case finding if no effective preventive measures are available. In this respect a distinction between asthma and COPD must be made. In asthma there is good evidence that early treatment with inhaled corticosteroids is effective $[2,15]$ and that postponing this treatment might cause deteriorating (irreversible) effects in terms of inflammation [15]. Whether this could be extrapolated to irreversible effects on lung function (fig. 4) is not clear. Even in nondiagnosed subjects with early indications of asthma, inhaled steroid treatment has shown to be useful [31]. However, in COPD only high-dose inhaled corticosteroids have been shown to have an effect (particularly in more severe obstruction with more exacerbations) [32, 33], but the long-term effects on lung function have proven disappointing $[33,34]$. The most effective treatment for COPD available at the moment is smoking cessation. There is mounting evidence that the rate of development of COPD can be reduced when patients at risk of developing the disease stop smoking. Moreover,

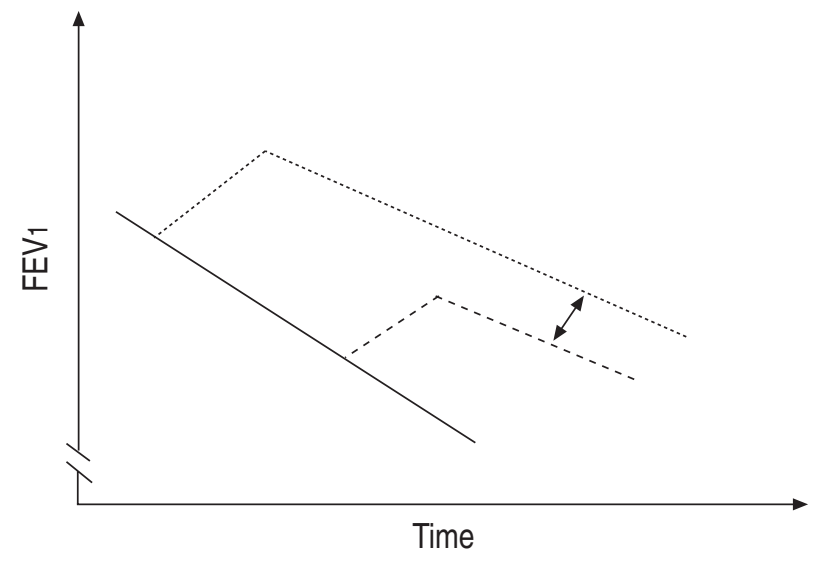

Fig. 4.- The (theoretical) progression of asthma, in terms of decline in lung function, when treatment with inhaled corticosteroids is initiated early $(\cdots \cdots)$, when it is postponed (----) or when it is not used at all (-). Arrow indicates (irreversible) loss of lung function when treatment is postponed.

there is also good evidence that smokers are much more motivated to stop smoking when they know that they are at risk of developing a chronic lung disease. The first indications came from a study using a longitudinal cohort, which showed that subjects who continued to smoke had a much steeper decline in lung function than those who stopped smoking, while smokers who stopped smoking had a steeper decline than never smokers [35]. Important evidence has come from the Lung Health Study [36], which confirmed that smoking cessation could reverse the steep decline in lung function. Further follow-up showed that attempts to quit smoking could prevent loss of lung function, especially in patients with mild COPD [37]. It also resulted in fewer respiratory symptoms after prolonged abstinence [38]. It is widely known that it is difficult to get smokers to quit. However, there are clear indications that smokers are much more intrinsically motivated to stop smoking if they realise that their respiratory complaints are caused by smoking and that they are at risk of developing COPD [39] or other smoking-related diseases [40].

When a smoker with a severely declined lung function stops smoking, he/she will not recover lost lung function, but the subsequent decline in lung function is likely to revert to normal [11]. Smoking cessation in an early stage of the disease has been demonstrated to improve prognosis $[11,35,36]$. There are even indications that the cessation of smoking in an early phase of COPD is more effective than in a later phase [41] (fig. 5). However, not all smokers develop COPD: only $24-47 \%$ of all smokers develop airflow obstruction, depending on the number of cigarettes smoked per day [11]. The knowledge that a smoker at risk of developing a smoking-related disease is more motivated to stop smoking than someone who is not at risk [39] might help a physician in encouraging an attempt to quit. It seems that GPs are already using this knowledge, as they seem more likely to advise smokers to quit smoking if they perceive symptoms to be smoking-related. 


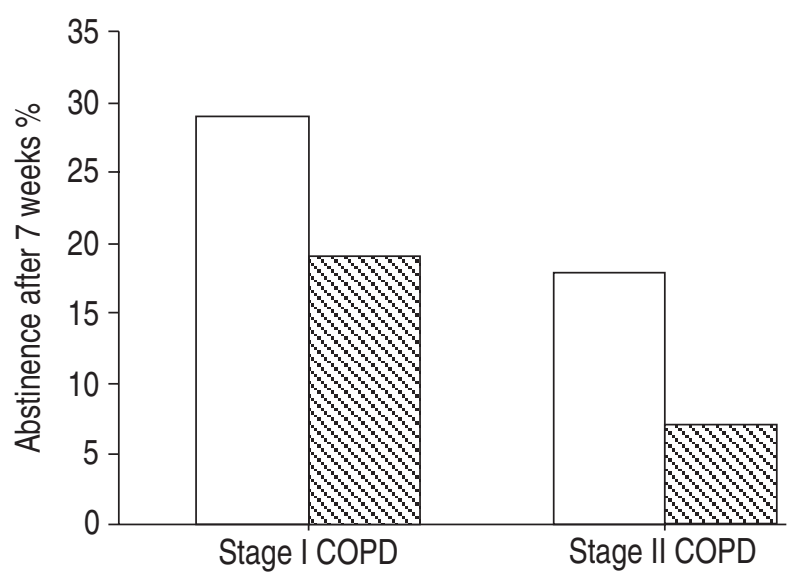

Fig. 5.- Per cent abstinence after 7 weeks of treatment with bupropion $(\square)$ or placebo $(\mathbb{\nabla})$ in different stages of chronic obstructive pulmonary disease (COPD) (according to the Global initiative for Chronic Obstructive Lung Diseases). Modified from [41].

\section{What is a feasible detection method in primary care?}

Screening the general population for respiratory symptoms and lung function has been shown to be an effective method for detecting subjects with a mildly but persistently impaired lung function at an early undetected stage of the disease [12]. When compared to other diseases, the cost per detected case is even relatively cheap [12] (table 1). In the daily routine of a general practice, however, screening the general population is not a feasible option. Thus, selecting is mandatory if one wishes to trace patients in general practice.

Case finding of COPD in general practice is clearly a more realistic approach than screening. But what criteria should be used for case finding, is it a feasible method for general practice and how should patients be selected? Since smoking is the most important risk factor for developing COPD and smoking cessation is the most effective intervention at every stage of the disease, the first step should be to select smokers. In a recently published study the current authors found that in a random group of smokers visiting the general practice, one patient at risk of COPD (defined as an obstructed FEV1 of $<80 \%$ pred) was found for every five to six smokers tested [42]. This positive predictive

Table 1. - Cost per detected case in screening programmes Disease Cost per detected case $€$

Hypertension
Abdominal aortic aneurysm
COPD/asthma
Hypercholesterolaemia
Prostate cancer
Breast cancer
Glaucoma
Down's syndrome
Cystic fibrosis
HIV

127
508
573
1117
$4060-6598$
$5786-23753$
13196
50755
$63951-317219$
125872

COPD: chronic obstructive pulmonary disease; HIV: human immunodeficiency virus. value of $18 \%$ was increased to $27 \%$ when this was restricted to coughing smokers. This means that approximately four people have to be tested for every coughing smoker at risk found. The positive predictive value of at least two of the symptoms from the list of coughing, dyspnoea and wheezing was only slightly higher, namely $29 \%$, which means that there is only some additional value in asking for other symptoms than coughing.

The authors also evaluated the time required for assessment in these surgeries. The mean time needed for an adequately performed spirometry was $\sim 4 \mathrm{~min}$. The mean time needed for detecting one patient with an FEV $1<80 \%$ in a group of smokers ranged 12-23 min, depending on the selection criteria used. However, a higher efficiency of detecting patients also means a larger number of persons at risk who are not detected. On the basis of these results and considerations of time efficiency, one could recommend testing all smokers who suffer from chronic coughing. It would then take $\sim 15 \mathrm{~min}$ of the practice assistant's time to find one case of a patient at risk of developing COPD.

Obviously, case finding depends on the quality of spirometry performed. Apart from the practice assistants' performance, the quality of the spirometric curve also depends on the device used and on the patient's co-operation. After a half-day training session, $84 \%$ of the spirometric curves obtained appeared to be of sufficient quality to determine FEV1 [42], according to American Thoracic Society criteria [43]. FEV1 measurements in general practice can be performed by the practice assistant, after a relatively brief instruction and training session [44].

The answer to the question if and when case finding of patients with airflow obstruction who are not known to their doctor is feasible depends on several factors, as follows: the way subjects are selected, the time needed to perform the assessment, the availability of skilled staff, the quality of the assessment, the availability of a suitable spirometer, the doctor's knowledge, a suitable room and, of course, a cooperative patient. Case finding of COPD seems to be a suitable method in general practice. Fifty years ago, it was thought unrealistic to let practice assistants measure blood pressure. Nowadays there is no longer any doubt about the ability of practice nurses or assistants to measure blood pressure adequately. By testing one coughing smoker a day, one or two patients at risk will be found every week. All these patients are at high risk of developing COPD. They should be carefully followed up and at least be encouraged to give up smoking.

When respiratory symptoms develop, the link with smoking habits should be made without restraint. As mentioned previously, successful cessation will be reached more easily when the patients present with symptoms. It is therefore imperative that computerised practice registration systems are incorporated with practical modules of smoking history, results of lung function testing and current smoking status. The GP will thus be facilitated in encouraging smoking cessation in patients at high risk of developing COPD. In practical terms, this strategy starts with registering 
smoking habits in every patient enlisted. Ideally, this registration should include current smoking status and pack-years, results of lung function testing and exacerbations over the years. With this in mind, the consensus statement from the US National Lung Health Education Program recommends the widespread use of office spirometry by primary care providers for patients $>45$ yrs old who smoke cigarettes and also for patients with respiratory symptoms such as chronic cough, episodic wheezing and exertional dyspnoea, in order to detect airway obstruction due to asthma or COPD. This new type of spirometry, office spirometry, allows lower instrument cost, smaller size, less effort to perform the test, improved ease of calibration checks and an improved quality-assurance programme [45]. In automatic registration systems it is possible to alert the user when the information has become outdated, which is especially useful in patients who visit their physician only at infrequent intervals. Such systems should enable the physician or assistant to keep track of smoking history, just as the record of each patient shows a history of past illnesses. In this way, respiratory symptoms can be linked directly to high-risk smoking habits, potentiating a more powerful approach to promote smoking cessation. Conversely, it is of particular research interest to routinely report the smoking status on the death certificate, as many national monitoring systems seem to underestimate the hazards of tobacco [46].

\section{What can be expected in the future with regards to the burden of asthma and chronic obstructive pulmonary disease?}

As mentioned previously, the prevalence of COPD, in particular, is expected to grow; COPD will be the fifth leading cause of disability and the third leading cause of death in the coming decades [6].

On the basis of different theoretical scenarios, the effect of smoking and smoking cessation on costs due to smoking in 2010 in the Netherlands has been estimated [47].

In this study, three different scenarios considering the impact of smoking cessation on the development of COPD were modelled (table 2): 1) a reference scenario which primarily predicts the impact of ageing, 2) an "attainable" smoking reduction scenario, and 3) an "extreme" smoking reduction scenario.

Table 2. - Scenarios of the impact of smoking: a reference scenario, an attainable and an extreme reduction scenario

Additions to reference scenario

$\begin{array}{cc}\begin{array}{c}\text { Attainable } \\ \text { reduction }\end{array} & \begin{array}{c}\text { Extreme } \\ \text { reduction }\end{array}\end{array}$

\begin{tabular}{lcc}
\hline Decrease in starting & 20 & 40 \\
Increase in quitting & 14 in 1998 & 14 in 1990 \\
In later years & 2 & 7 \\
Smokers in 2010 & $20-25$ & 8 \\
\hline
\end{tabular}

Data are presented as \%. Data are reproduced with permission from [47].

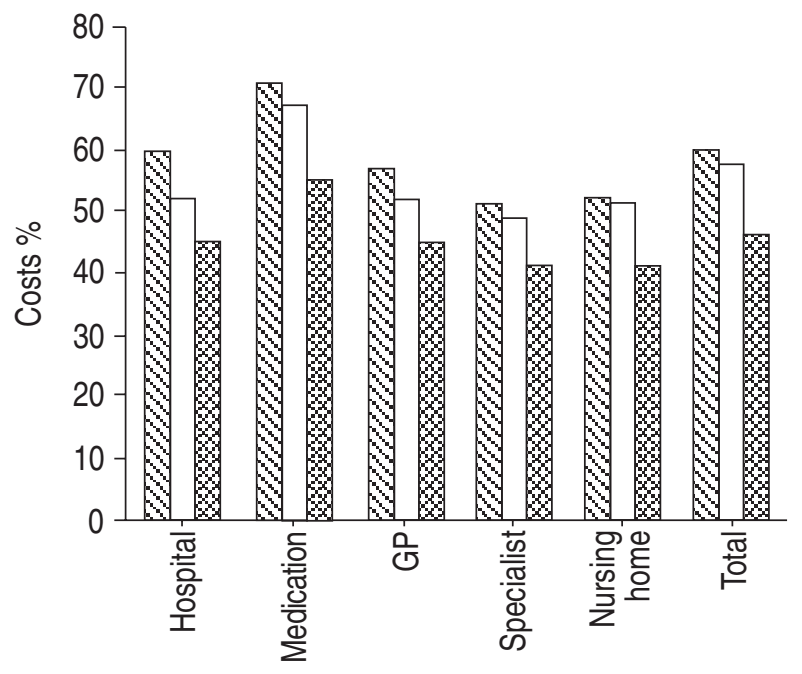

Fig. 6.-Per cent costs due to the increase in asthma/chronic obstructive pulmonary disease in the Netherlands in three different stop smoking scenarios: reference scenario $(\mathbb{\mathbb { Q }})$; attainable reduction scenario $(\square)$ and extreme reduction scenario ( $)$. GP: general practitioner. Figure reproduced with permission from [47].

Figure 6 shows that the reference scenario predicted the costs to increase by $60 \%$ in 2010 . COPD prevention as modelled in the second scenario reduced the projected cost increase from 60 to $57 \%$. In the third scenario there was only a $48 \%$ increase. This indicates that even an extreme smoking reduction scenario will not lead to direct large effects in health economical terms. It will only have an impact on the very long term both on morbidity and on total healthcare costs, which makes the intervention difficult as (health) politicians normally think in shortterm and not in long-term effects.

Considering that COPD is one of the main diseases in the Western world and that it will continue to increase (while mortality rates for cardiovascular diseases seem to show a declining trend), smoking cessation will become even more important than it already is, although the effects on costs will need a larger period to become apparent.

In the developing world, efforts of major tobacco companies to increase their markets have been enormous in the past few years, and this will most certainly lead to alarming smoking prevalences in the large populations of Asia, Africa and Latin America. In China, with $20 \%$ of the world's population smoking $30 \%$ of the world's cigarettes, massive retrospective and prospective studies have been undertaken to predict the development of deaths attributable to tobacco use. On the basis of current smoking patterns, the number of tobacco deaths in China is estimated to rise from 0.6 million in 1990 to about 3 million deaths a year by the middle of the century [48, 49]. These predictions of a large increase in tobacco-attributable mortality were supported by case-controlled data from Hong Kong, where cigarette consumption reached its peak 20 yrs earlier than in mainland China. In 1998, tobacco caused $33 \%$ of all male deaths at ages 25-69 yrs in Hong Kong [50].

What these studies are telling us is that the future 
focus should be worldwide. If current smoking patterns persist it has been estimated that by $\sim 2030$ cigarettes will cause 3 million deaths a year in the western world, as opposed to 7 million deaths yearly in the developing world [46].

\section{References}

1. Tirimanna PRS, van Schayck CP, den Otter JJ, et al. Prevalence of asthma and COPD in general practice in 1992: has it changed since 1977? Br J Gen Pract 1996; 46: 277-281.

2. Dompeling E, van Schayck CP, van Grunsven PM, et al. Slowing the deterioration of asthma and chronic obstructive pulmonary disease observed during bronchodilator therapy by adding inhaled corticosteroids. Ann Int Med 1993; 118: 770-778.

3. Renwick DS, Conolly MJ. Prevalence and treatment of chronic airways obstruction in adults over the age of 45. Thorax 1996; 51: 164-168.

4. Siafakis NM, Vermeire P, Pride NB, et al. ERSconsensus statement. Optimal assessment and management of chronic obstructive pulmonary dissease (COPD) Eur Respir J 1995; 8: 1398-1420.

5. Fiel SB. Chronic obstructive pulmonary disease, mortality and mortality reduction. Drugs 1996; 52: Suppl. 2, 55-61.

6. Murray CJL, Lopez AD. Mortality by cause for eight regions of the world: global burden of disease study. Lancet 1997; 349: 1269-1276.

7. van den Boom $G$, van Rutten-Molken MPMH, Tirimanna PRS, van Schayck CP, Folgering $H$, van Weel C. Association between health-related quality of life and consultation for respiratory symptoms: results from the DIMCA programme. Eur Respir J 1998; 11: 67-72.

8. Burdon JWG. Chronic lung disease and the perception of breathlessness: a clinical perspective. Eur Respir J 1994; 7: 1342-1349.

9. Barnes PJ. Poorly perceived asthma. Thorax 1992; 47: 408-409.

10. Thoracic Society of Australia and New Zealand. Guidelines for the management of chronic obstructive pulmonary disease. Mod Med Aust: 1995: 132-146.

11. Fletcher C, Peto R, Tinker C. The natural history of chronic airflow obstruction. BMJ 1977; 1: 1645-1648.

12. van den Boom $\mathrm{G}$, van Schayck $\mathrm{CP}$, van Rutten-Mölken $\mathrm{MPMH}$, et al. Active detection of COPD and asthma in the general population: results and economic consequences of the DIMCA programme. Am J Resp Crit Care Med 1998; 158: 1730-1738.

13. Speight AN, Lee DA, Hey EN. Underdiagnosis and undertreatment of asthma in childhood. BMJ 1983; 286: 1253-1256.

14. Barnes PJ. Blunted perception and death from asthma. N Engl J Med 1994; 30: 1383-1384.

15. Haahtela $\mathrm{T}$, Järvinen $\mathrm{M}$, Kava $\mathrm{T}$, et al. Effects of reducing or discontinuing inhaled budesonide in patients with mild asthma. $N$ Engl J Med 1994; 331: 700-705.

16. Levy M. Delay in diagnosing asthma. Is the nature of general practice to blame? J Roy Coll Gen Prac 1986; 36: 52-53.

17. Brand PLP, Rijcken B, Schouten JP, Koeter GH, Weiss ST, Postma DS. Perception of airways obstruction in a random population sample: relationship to airways hyperresponsiveness in the absence of respiratory symptoms. Am Rev Respir Dis 1992; 146: 396-401.

18. Kendrick AH, Hoggs CMB, Whitfield MJ, Laszlo G. Accuracy of perception of severity of asthma patients treated in general practice. BMJ 1993; 307: 422-424.

19. Bijl-Hofland ID, Cloosterman SGM, Folgering HThM, Akkermans RP, van Schayck CP. Relation of the perception of airway obstruction to the severity of asthma. Thorax 1999; 54: 5-19.

20. Rabe KF, Vermeire PA, Soriano JB, Maier WC. Clinical management of asthma in 1999: the asthma insights and reality in Europe (AIRE) study. Eur Respir $J$ 2000; 16: 802-807.

21. Levy M, Bell L. General practice audit of asthma in childhood. BMJ 1984; 289: 115-116.

22. Gellert AR, Gellert SL, Iliffe SR. Prevalence and management of asthma in a London inner-city general practice. Br J Gen Pract 1990; 40: 197-201.

23. Horn CR, Cochrane GM. Management of asthma in general practice. Respir Med 1989; 83: 67-70.

24. Blainey D. The cost of acute asthma - how much is preventable? Health Trends 1990-91; 22: 151-153.

25. British Thoracic Association. Death from asthma in two regions of England. BMJ 1982; 285: 1251-1255.

26. van Schayck CP, van der Heijden FMMA, van den Boom G, Tirimanna PRS, van Herwaarden CLA. Underdiagnosis of asthma: is the doctor or the patient to blame? The DIMCA project. Thorax 2000; 55: $562-565$.

27. Bestall JC, Paul EA, Garrod R, Garnham R, Jones PW, Wedzicha JA. Usefulness of the Medical Research Council (MRC) dyspnoea scale as a measure of disability in patients with chronic obstructive pulmonary disease. Thorax 1999; 54: 581-586.

28. Hajiro T, Nushimura MT, Ikeda A, Koyama H, Izumi T. Analysis of clinical methods used to evaluate dyspnea in patients with chronic obstructive pulmonary disease. Am J Respir Crit Care Med 1998; 158: $1185-1189$.

29. Neville RG, Bryce FP, Robertson FM, Crombie IK, Clark RA. Diagnosis and treatment of asthma in children: usefulness of a review of medical records. $\mathrm{Br}$ J Gen Pract 1992; 42: 5001-5003.

30. Bryce FP, Neville RG, Crombie IK, Clark RA, McKenzie P. Controlled trial of an audit facilitator in diagnosis and treatment of childhood asthma in general practice. BMJ 1995; 310: 838-842.

31. van den Boom $G$, van Rutten-Mölken MPMH, Molema J, Tirimanna PRS, van Weel C, van Schayck CP. The cost-effectiveness of early treatment with fluticasone propionate $250 \mu \mathrm{g}$ twice daily in subjects with obstructive airway disease, detected by a two stage screening program. Am J Respir Crit Care Med 2001; 164: 2057-2066.

32. Paggiaro PL, Dahle R, Bakran I, Frith L, Hollingworth K, Efthimiou J. Multi centre randomized placebo controlled trial of inhaled fluticasone propionate in patients with chronic obstructive pulmonary disease. Lancet 1998; 351: 773-780.

33. Burge PS, Calverley PMA, Jones PW, Spencer S. Randomised, double blind, placebo controlled study of fluticasone propionate in patients with moderate to severe chronic obstructive pulmonary disease: the ISOLDE trial. BMJ 2000; 320: 1297-1303.

34. Vestbo J, Sørensen T, Lange P, Brix A, Torre P, Viskum K. Long-term effect of inhaled budesonide in 
mild and moderate chronic obstructive pulmonary disease: a randomised controlled trial. Lancet 1999; 353: 1819-1823.

35. Xu X, Dockery DW, Ware JH, Speizer FE, Ferris BG. Effects of cigarette smoking on rate of loss of pulmonary function in adults: a longitudinal assessment. Am Rev Respir Dis 1992; 146: 1345-1348.

36. Anthonisen NR, Conett JE, Kiley JP, Altose MD, Bailey WC, Buist AS. Effects of smoking intervention and the use of an inhaled anticholinergic bronchodilator on the rate of decline of FEV1: the Lung Health Study. JAMA 1995; 273: 1497-1505.

37. Murray RP, Anthonisen NR, Connett JE, et al. Effects of multiple attempts to quit smoking and relapses to smoking on pulmonary function. $J$ Clin Epid 1998; 51: 1317-1326.

38. Kanner RE, Connett JE, Williams DE, Buist AS. Effects of randomised assignment to a smoking cessation intervention and changes in smoking habits on respiratory symptoms in smokers with early chronic obstructive pulmonary disease: the Lung Health Study. Am J Med 1999; 106: 410-416.

39. Zielinsky J, Bednarek M. Early detection of COPD in a high-risk population using spirometric screening. Chest 2001; 119: 731-736.

40. Humerfelt S, Eide GE, Kvale G, Aarø LE, Gulsvik A. Effectiveness of postal smoking cessation advice: a randomised controlled trial in young men with reduced FEV1 and asbestos exposure. Eur Respir $J$ 1998; 11: 284-290.

41. Tashkin DP, Kanner R, Bailey W, et al. Smoking cessation in patients with chronic obstructive pulmonary disease: a double-blind, placebo-controlled, randomised trial. Lancet 2001; 357: 1571-1575.
42. van Schayck CP, Loozen JMC, Wagena E, Akkermans RP, Wesseling GJ. Detecting patients with a high risk for developing COPD. A prospective case-finding study of smokers in general practice. BMJ 2002; 324: 1370-1373.

43. American Thoracic Society. Lung function testing: Selection of reference values and interpretative strategies. Am Rev Respir Dis 1991; 144: 1202-1218.

44. Schermer TRJ, Folgering HTM, Bottema BJAM, Jacobs JE, van Schayck CP, van Weel C. The value of spirometry for primary care: Asthma and COPD. Prim Care Respir J 2000; 9: 48-52.

45. Ferguson GT, Enright PL, Buist SA, Higgins MW. Office spirometry for lung health assessment in adults. A consensus statement from the national lung health education program. Chest 2000; 117: 1146-1161.

46. Lopez AD. Counting the dead in China. BMJ 1998; 317: 1399-1400.

47. van Rutten-Mölken MPM, Postma MJ, Joore MA, van Genugten MLL, Leidl R, Jager JC. Current and future medical costs of asthma and chronic obstructive pulmonary disease in the Netherlands. Respir Med 1999; 93: 779-787.

48. Liu BQ, Peto R, Chen ZM, et al. Emerging tobacco hazards in China: 1. Retrospective proportional mortality study of one million deaths. BMJ 1998; 317 : 1411-1422.

49. Niu SR, Yang GH, Chen ZM, et al. Emerging tobacco hazards in China: 2. Early mortality results from a prospective study. BMJ 1998; 317: 1423-1424.

50. Lam TH, Ho Y, Hedley AJ, Mak KH, Peto R. Mortality and smoking in Hong Kong: case-control study of all adult deaths in 1998. BMJ 2001; 323: 361-367. 